\title{
The Practices and Challenges of Fiscal Decentralization: A Case of Bedelle Woreda,
} Oromia Region, Ethiopia

Tesfaye Gudeta* Minhaj Alam ${ }^{* *}$ Damena Tolassa**

\begin{abstract}
The study's main objective was assessing the practices and challenges of fiscal decentralization at Bedelle woreda, with particular reference to basic selected sectors (Education, Agriculture, Health, Water, and Road). According to the nature of this study, a descriptive research design with qualitative and quantitative methods was adopted. The population of the study was government employees working in selected sectors of Bedelle Woreda. The census sampling technique was used in this research because the study population was manageable. To this effect, 128 participants were selected using a census sampling size. Besides this, Woreda (District) Finance and Economic Development and Woreda Revenue Office Authority officials were purposely selected to conduct interviews. The data-gathering instruments were questionnaires, key informant interviews, and document analyses. Descriptive and inferential statistical techniques were used for data analysis. In descriptive using frequencies and percentages and inferential statistics, multiple linear regression was used to assess relationships between the independent variables (legal framework, revenue, expenditure, employee experience, employee training, management commitment, and fiscal transfers) and the dependent variable (fiscal decentralization). The findings show that internal revenue raising and utilization in the selected sectors was very low. Besides, lack of autonomy in expenditure decisions of sectors, insufficient capacity building, the extent of fiscal transfer, and financial resource were the major challenges in the study area. Overall, the regression analysis revealed that, Revenue raising $(\beta=-0.164$, $p<0.05)$, Expenditure decision $(\beta=0.236, p<0.05)$, Employee experience $(\beta=0.525, p<0.05)$, and Commitment of management $(\beta=0.172, p<0.05)$, all have statistically significant and positive effect on fiscal decentralization. Based on the study's findings, it is recommended that existing legal frameworks be modified to enable the sectors to use their budget in line with their action plan to generate and utilize sufficient revenues. Special emphasis should be given to an employee's capacity building, independence of planning and budgeting, and clear autonomy of expenditure assignments. Inter-governmental fiscal relations should also be planned to reduce the horizontal imbalances observed at selected sectors of the woreda under study.
\end{abstract}

Keywords: Fiscal Decentralization, Revenue Assignment, Expenditure Assignment, Fiscal Transfers, Bedelle

\footnotetext{
Metu University, Ethiopia. Email: tesfayegudeta2030@gmail.com

** Jimma University, Email: prof.minhajalam@gmail.com

*** Jimma University, Email: ibsaabbageda2006@gmail.com
} 


\section{PanAfrican Journal of Governance and Development, Vol. 2, No. 2, August 2021}

\section{Introduction}

As one of the major dimensions of decentralization, fiscal decentralization has been a worldwide phenomenon since the 1990s (Abu, 2005). The fiscal decentralization framework must link local financing and fiscal authority to the local government's service provision responsibilities and functions so that local politicians can bear the cost of their decisions and deliver on their promises. It helps to bring economic and political systems closer to local communities (ibid).

Since the last decade of the twenty-one century, many developing countries are experimenting with fiscal decentralization to improve their governance and economic growth. Fiscal decentralization is the transfer of financial power from the center to local bodies. A growing number of countries have adopted it in an effort to improve the performance of their public sectors (Abu, 2005). Fiscal decentralization mainly deals with functional assignment, tax assignment, and intergovernmental fiscal relation among different tiers of governments in a federation (Mbedzi and Gondo, 2010).

After independence, sub-Saharan African countries inherited a highly centralized model of the territorial government and fiscal arrangements. Therefore, in the last quarter of the twentieth century, many countries have engaged in decentralization by transferring federal responsibilities to lower tiers of government. Fiscal decentralization reforms started gaining momentum in subSaharan Africa in the early 1990s. Fiscal decentralization is most advanced in three sub-Saharan African countries Ethiopia, Nigeria, and South Africa, where spending at the subnational government level represents about half of total general government spending (IMF, 2006).

The 1991 government change in Ethiopia has ushered in a decentralized system of governance. Decentralization in Ethiopia hopes to bring about harmony and cooperation between different groups and promote local self-rule. The FDRE Constitution shared government powers between federal and regional states. The regions are divided into zones, woredas, urban administration, and kebeles (villages). The zones are regarded as agents of regional states, while woredas are regarded as the key local government unit of the region with significant responsibility for providing basic service (Deribe, 2015).

The FDRE Constitution of Ethiopia is a source to guarantee fiscal decentralization and autonomy of local government in Ethiopia. Article 50(4) states that the regional state government grants the lowest level government units adequate power. The region has decentralized autonomy with 
respect to local revenue to its cities/towns or woredas on revenue-raising and expenditure management.

The Oromia regional state constitution defined the duties and responsibilities of the woreda administration and gave them the autonomy of revenue generation and finance given and expenditure prioritization while planning. Therefore, woredas have been empowered to deliver basic services within their respective jurisdiction. There is a broad consensus that the woreda level decentralization program (WLDP) is key to improving local economic development by enhancing service delivery and local empowerment (Minhaj A and Dabela B, 2018).

\section{Statement of the Problem}

Since the 1980s at the global level and 1991 in Ethiopia, the decentralization reform program was to empower the local institutions as service providers. Oommen (2008) quoted in (Deribe, 2015) Ethiopia attempted to introduce federalism in general and fiscal decentralization in particular since the time of transition period (1991-1994). The Proclamation No.7/1992 provides for the establishment of Regional self-governments with broad power:

i. Planning and directing economic and social establishments

ii. Preparing, approving, and implementing their own budgets

iii. Borrowing from domestic sources; and levying taxes and dues to a wellfunctioning decentralization system in Ethiopia, the government has endorsed woreda level decentralization programs in general and fiscal decentralization in particular since 2002 .

However, the woreda level fiscal decentralization practices face a set of challenges in Ethiopia (Eyob, 2017). Some of the previously conducted researches indicated the problems related to woreda level fiscal decentralization. For instance, Eyob (2017) researched the appraisal of woreda-level fiscal decentralization in the Addis Ababa city government and concluded that woreda administrations had a weak revenue base and expenditure assignment autonomy. Abraham (2011) conducted research on the implementation of woreda level decentralization in Gambella Regional State, and he concluded that the expenditure and revenue assignment of woredas is limited to the region. Similarly, Minhaj, A and Dabela B (2018) conducted their research on the assessment of fiscal decentralization at Sibu Sire woreda and concluded that the 


\section{PanAfrican Journal of Governance and Development, Vol. 2, No. 2, August 2021}

very purpose of implementing fiscal decentralization does not fulfill the criteria of fiscal autonomy to the woreda.

However, the previous study did not assess the practice and the main challenges of fiscal autonomy at the woreda level, particularly the major public sectors. Moreover, no empirically conducted study on the practices and challenges of fiscal decentralization is available in the study area. Hence, this study tried to fill this gap by assessing the practices and challenges of fiscal decentralization with particular reference to selected public sectors in the study area.

The study's main objective was investigating the practices and challenges of fiscal decentralization at Bedelle woreda, with particular reference to selected basic sectors. The specific objectives of the study include: i) To describe the legal frameworks to practices of fiscal decentralization; ii) To assess the practice of revenue generation of fiscal decentralization; iii) To assess the practice of expenditure authority of fiscal decentralization; iv) To assess the challenges related to the practices of fiscal decentralization; v) To evaluate the extent of the fiscal gap between revenue and expenditure.

Although the study brought relevant information in the study area on the challenges that limit the proper practices of fiscal decentralization, and it also helped different stakeholders (policymakers, researchers) to increase the awareness and understanding about practices and the challenges of fiscal decentralization in the country in general and at woreda level in particular. Decentralization is a broad initiative in the Development Strategies of Ethiopia that involves multiple actors and factors at its phase of adoption and implementation (Demelash, 2011).

However, this is limited to the fiscal decentralization to make more specific and selected basic government sectors include: Education, Health, Agriculture, Water, and Rural Road Sectors. These sectors are selected purposively in terms of their budget allocation and service delivery at the local level, and due to their main role in realizing the national development objectives, they require real implementation of fiscal decentralization. The study has delimited to three areas of fiscal decentralization: revenue, expenditure, and grants and geographically delimited to Bedelle Woreda in Bunno Bedelle Zone, Oromia Regional State and mainly focused on the assessment of practices and challenges of fiscal decentralization in the area of revenue, expenditure, and grant to selected sectors of woreda. 


\section{Review of Literature}

\section{The Concept of Fiscal Decentralization}

Fiscal decentralization, one of the forms of decentralization, generally refers to the devolution of taxing and spending powers from the control of central government authorities to government authorities at sub-national levels (regional, provincial, municipal, woreda, etc.). In a highly decentralized system, local governments have considerable power to mobilize resources through taxing authorities accompanied by strong tax bases (Bird, Richard M., 2008).

Fiscal decentralization who sets and collects what taxes, who makes what expenditures, and how any vertical imbalance is rectified has been especially prominent in recent discussions in many countries, but as just indicated, many of the more fundamental questions related to political and administrative decentralization (Inman and Rubin Feld, 1997).

Fiscal decentralization refers to the structure of financial and broader relationships between central and subordinate levels of government. The process of altering the structure of fiscal decentralization by devolving powers to lower levels of government is generally known as fiscal decentralization. Essentially, fiscal decentralization is a specific process meant to alter the financial state of affairs (Boschmann, 2009).

Scholars suggest that fiscal decentralization is more efficient by allowing local governments to determine the appropriate level of service delivery and creating competition between local governments while allowing voters to move from one jurisdiction to another to obtain an optimal preference of service provision (Smith, 2012).

\section{Fiscal Decentralization Theory}

\section{Theoretical Arguments}

The prominent writer Oates (1972) affirms that decentralization enhances economic efficiency because local governments have better knowledge of local conditions and preferences or the provision of the public good than national/central governments due to their physical and institutional proximity. This informational proximity allows local government to deliver public goods and services that better match local preferences or deliver the same public goods and services at a lower cost at the same time by diversifying government output. Oates further argues that decentralization at higher levels of public goods and services across jurisdictions will 


\section{PanAfrican Journal of Governance and Development, Vol. 2, No. 2, August 2021}

generally be inefficient; the larger variance in regional demands for public goods, the larger benefits of fiscal decentralization.

According to Rodrigues, A., and A. Kroijer (2009), cause of the enhanced proximity between those governing and those governed, fiscal decentralization empowers individuals and helps to generate institutions such as greater trust, interaction, and networking, in turn, it contributes to a reduction of the transaction cost. Finally, Smoke Paul (2009) argues there can be no argument with analysis that points to potential macro-economic dangers and growth retarding effects of fiscal decentralization; most of the evidence, however, is anecdotal relevant only under particular uncommon circumstances focused on correctable rather than inherent problems. The reality is that the appropriate degree of decentralization will vary with the context of particular countries, and some steps can be taken in most countries to neutralize potential macro-economic dangers. Simply decentralizing is not going to bring development, and failing to decentralize will not necessarily undermine it.

The theory of fiscal decentralization addresses three issues related to fiscal decision-making: assignment of responsibilities and functions between the federal government and sub-national governments, the assignment of taxation power, and the design of intergovernmental transfer (subsidy) of fiscal resources coupled with provisions about the borrowing windows to subnational governments (Abu, 2005).

\section{Key Factors for Effective Decentralization Process in Local Government}

Decentralization demands some kind of commitment and also the existence of well-framed institutional structures to encourage the development effort both at national, regional, and local levels (Litvack, 2005). These scholars indicated the following points that are necessary conditions for effective decentralization. These are:

i. Political commitment is of intrinsic importance to decentralized service delivery for several reasons. It is widely accepted that political commitment on the part of federal or state governments is a sine qua non of effective democratic decentralization, especially forms of decentralization that are specifically geared to the interests of the poor.

ii. Effective inter-organizational relations in recognition of the latent power of organized civic protest, local authorities in different countries have experimented with 
institutional arrangements designed to facilitate public engagement, feedback, and oversight.

iii. Availability and access to resources required is a critical determinant of the equity, quality, and efficiency of public services, and the inadequacy of financial resources often explains poor service outcomes. Lack of resources implies incapacity of any agency. Most developing countries are constrained mainly by a lack of finance to implement decentralization policies.

iv. The capacity of implementing institutions is an actual decentralization that has to be institutionalized and integrating their own organizational policies into practice.

v. Training program in the district to equip staff with the necessary knowledge has been initiated to capacitate to bring forward decentralization of services at local levels. In his study, Ali (2018) stated that international partners have mostly provided training, but the local government lacks a budget allocated to staff training.

\section{Fiscal Decentralization in Ethiopia: Empirical Review}

The 1995 Federal Constitution is the basic document that lays out the legal and institutional framework for decentralization in Ethiopia. The decentralization reforms focus on strengthening local governments as institutions of democratic governance and efficient service delivery. It also outlined the respective spheres of authority and responsibilities of the Federal Government and the Regional States (WorldBank, 2010)

Currently, fiscal decentralization is seen as part of a reform agenda to strengthen regional and local governments. In contrast, Smith (2012) suggests that local governments or administrative units possess the legal authority to impose taxes in many developing countries, but the tax base is so weak and the dependence on central government subsidies so ingrained that no attempt is made to exercise their authority. This is because the central government alone cannot satisfy all of the competing needs of its constituent units. Besides, local and regional governments help to implement national economic development strategies, which can be more reliable with adequate taxation powers to meet their expenditure responsibility (Kena, 2016).

As initiated in the Transitional Charter and reaffirmed by the 1995 Constitution of the Federal Democratic Republic of Ethiopia, the Ethiopian federal system has introduced political, administrative, and fiscal decentralization to ensure the right to self-administration (Zemenu, 


\section{PanAfrican Journal of Governance and Development, Vol. 2, No. 2, August 2021}

2016). Accordingly, Ethiopian fiscal decentralization reform followed the political imperative of establishing a federal political structure (Aberra, 2015). Currently, Ethiopia is among those African countries with constitutions in which self-rule and the existence of local governments are formally recognized (World Bank, 2001). Furthermore, the government has introduced constitutional, administrative, and institutional reforms to deepen and broaden the decentralization process to Woreda through Woreda/District Level Decentralization Program (DLDP) in 2001 World Bank, (2001).

So far, two phases of decentralization have been put in place in the current government administration: The first wave of decentralization (1991-2001) and devolution of powers and responsibilities at the Woreda level since 2002. The first wave of decentralization aimed to create and empower national and regional governments, whereas the second phase of decentralization concerned the devolution of powers at woreda levels - lower levels of administration (Deribe, 2015). Similarly, Aberra (2015) found that beginning from 2001/2, regional states decided to transfer major responsibilities and resources to the Woreda level. In these states, woreda became a legally sanctioned lower tier of government closest to the people and entrusted with significant responsibilities to plan, formulate, and implement policies on economic development and social services.

\section{Pillars of Fiscal Decentralization}

As initiated in the Transitional Charter and reaffirmed by the 1995 Constitution of the Federal Democratic Republic of Ethiopia, the Ethiopian federal system has introduced political, administrative, and fiscal decentralization to ensure the right to self-administration (Zemenu, 2016).

Fiscal decentralization has to do with the degree of fiscal autonomy and responsibility given to sub-national governments. Fiscal autonomy relates to the ability of the local jurisdiction both to raise enough revenues from the local economy and then to determine how to spend those revenues. It involves the ability of the jurisdiction to set tax rates and establish the revenues base without outside influence, as well as to have the ability to provide the service levels that the jurisdiction citizens demand. Smoke Paul (2009) stated that fiscal decentralization is the financial aspect of devolving to regional and local government consisting of three major issues. The following section discusses these three issues in detail. 


\section{Revenue Assignment}

The Ethiopian Constitution, from articles 94 to 100, FDRE Constitution clearly defined revenue assignments to each tier of the government besides borrowing and subsidies. Revenue assignment refers to vertical sharing of public resources (what share of the total government budget should be decentralized (Bird, Richard M., 2008). Regional and local taxation can introduce inefficiencies in allocating resources across the federation and cause inequities among people in different jurisdictions (Moges, 1994). The purpose of this provision is to make available income - or revenue - that determines how much there is to spend to implement policies and the costs of service delivery stipulated in the budget.

\section{Expenditure Assignment}

Assigning responsibilities for spending, including the exercise of regulatory functions, must precede the assignment of responsibilities for taxation because tax assignment is generally guided by the spending requirements of the different organs of government and cannot be determined in advance. It may also be said that expenditure assignment is more important than revenue assignment, for there are fundamental justifications to decentralize expenditure assignments than revenue assignments (Getachew, M (2011).

\section{Intergovernmental Transfer (subsidy)}

Intergovernmental fiscal relations must be thought of as a fiscal system to fill fiscal imbalance, and all the pieces of that system must fit together (Bird, Richard M., 2008). Fiscal imbalance refers to both vertical and horizontal regional imbalances. The former refers to an imbalance between revenue means and expenditure needs at different levels of government, while the latter refers to regional variations in correspondence between revenue base and expenditure requirement (Tegegne et al., 2007). There are two organs responsible for intergovernmental fiscal transfers in the Constitution. House of Federation (HOF) is the principal organ for this purpose; secondly, the federal government may directly be involved in the states' fiscal transfers. Article 62 (7) of the Constitution stipulates that it would determine the formula the federal government gives subsidies (grants) to the states.

\section{Challenges of Fiscal Decentralization in Ethiopia}

In Ethiopia, the concept of decentralization is influenced by a mix of economic, political, and social factors. According to Azfar O. et al. (2005), utilizing the concept of fiscal decentralization 
PanAfrican Journal of Governance and Development, Vol. 2, No. 2, August 2021

would be helpful to understand its dynamics fully. A host of factors is likely to influence the performance of fiscal decentralization in sub-national and local level governments; this study also confirms this argument in the study area. These include the political framework, fiscal aspects of decentralization; transparency of government actions; citizen participation; the effectiveness of civil society; aspects of the social structure, the capacity of sub-national governments, lack of autonomy, fiscal imbalance, and other factors were raised as major challenges.

\section{Conceptual Framework of the Study}

The study's conceptual framework has been contextualized following a review of related literature. This study has tried to identify the influence of independent variables on the dependent variable.

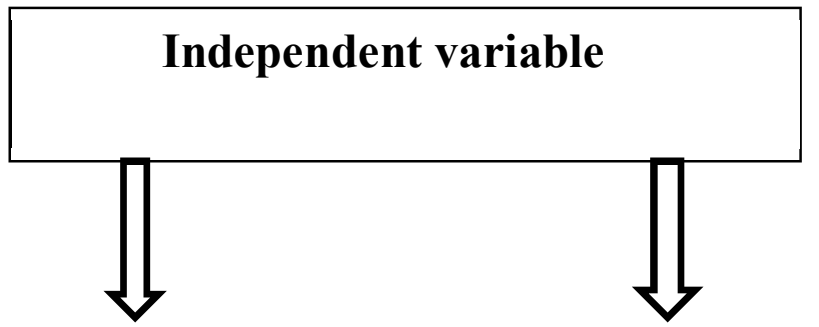

\section{Dependent variable}

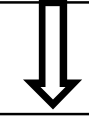

\begin{tabular}{l}
\hline Revenue assig \\
\hline Causes \\
Weak \\
revenue \\
base, lack of \\
capacity and \\
employee \\
experience, \\
Lack of \\
commitment \\
and other \\
factors
\end{tabular}

\section{Expenditure assignment}

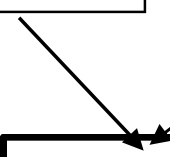

Fiscal imbalance;

Vertical and Horizontal gap

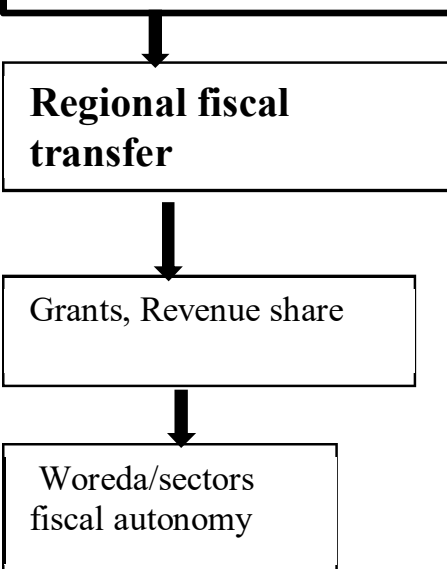

Budget on basic selected sectors; Health, Education, Agriculture, Water and Rural Road
Practice of Fiscal decentralization

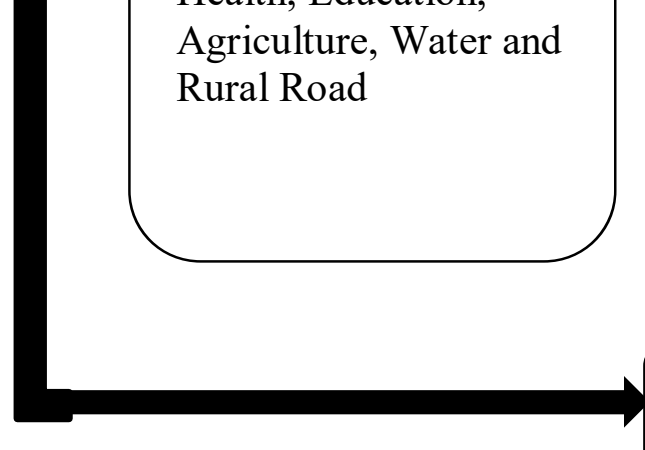

Challenges 
Figure 1: Conceptual Framework

Source: Developed by Authors (2020)

\section{Research Methodology}

\section{Research Approach and Design}

This study relies on a mixed research approach. Because using both quantitative and qualitative methods simultaneously is more advisable (Teshome, 1998). Because quantitative data provides precise summaries and comparisons, while qualitative data provided general elaborations, explanations, meanings, and relatively new ideas, therefore, this approach is more appropriate to investigate the topic under discussion on assessment of the practices and challenges of fiscal decentralization at Bedelle woreda with the selected basic sectors.

Kothari. C, (2004) argues that research design helps the researcher plan in advance of the methods adopted for collecting the relevant data and techniques to be used during analysis. Based on these theoretical arguments, the study employed a descriptive research design. Since the primary purpose of this study focuses on assessing the practices and challenges of fiscal decentralization at Bedelle woreda with selected sectors through collecting data related to people's opinions, then the descriptive design is appropriate.

\section{Sampling Techniques and size}

From 29 sectors in Bedelle woreda, five (5) basic sectors are selected using purposive sampling techniques. These sectors include - Education, Health, Agriculture, Water, and Rural road. The reasons for selecting these five basic sectors are because their budget allocation is more and these sectors play a crucial role in the development, and they considered poverty reduction sectors and prioritized under government policy. However, the researchers refer to five offices of selected sectors directly or indirectly related to the study for data collection like Woreda Office of Finance and Economic Development, Woreda Civil Service Office, and Woreda Administration purposively. The researcher used purposive sampling not to miss the target group and focus on particular characteristics of the population interested and best answer research questions.

According to the data obtained from the woreda civil service office, the total number of staff of the selected sectors is 128 (Male 94, Female 34). Therefore, the researcher used census sampling because the size of the study respondents is manageable. Census sampling uses the entire 


\section{PanAfrican Journal of Governance and Development, Vol. 2, No. 2, August 2021}

population as the sample and is more attractive for small populations (e.g., 200 or less) (Masuku, 2014).

So that, the key informants of the study were selected from the Woreda Office of Finance and Economic Development, Woreda Office of Revenue Authority, Woreda Civil Service Office and Woreda Administrator and the Managers and Vice Managers of selected sectors for in-depth interview purposively. Because the research requires those respondents who have a basic understanding of issues under investigation and the very purpose of using the respondents from staff helps to understand the other challenges of the practices of fiscal decentralization in the study area. The following table shows the sample size of the study.

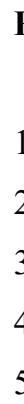

Ref
2
3
4
5

Ref .No

Selected Basic Sectors

Education sector

Health sector

Agriculture sector

Water sector

Rural road sector

Total
No of Staffs

$\begin{array}{lll}\text { M } & \text { F } & \text { T } \\ 21 & 4 & 25 \\ 20 & 11 & 31 \\ 38 & 12 & 50 \\ 8 & 4 & 12 \\ 7 & 3 & 10 \\ \mathbf{9 4} & \mathbf{3 4} & \mathbf{1 2 8}\end{array}$

Source: Bedelle Woreda Public Service Office (2020).

\section{Methods of Data Collection}

Based on the research problem and objectives, both primary and secondary data sources were used. For primary data collection, questionnaires and interviews were selected, while secondary data sources were document analysis like five consecutive fiscal years of the sectors under discussion. Moreover, the structured interview was conducted for key informants of the study, the managers and experts of selected sectors, Woreda Office of Finance and Economic Development manager, Woreda Civil Service leader, Woreda revenue authority leader, and the Woreda administrator were selected for interviewees and they considered as knowledgeable and rich to provide explanations on the study.

\section{Document Analysis and Reliability of Research Instruments}

Under this, the related written documents were reviewed and analyzed to collect the secondary data necessary for the study. This includes the Federal and Regional Constitutions, 
proclamations, WOFED documents budget, Woreda Revenue Authority Office document, and budget documents for each selected sector. For the reliability of the questionnaires, the researchers have conducted a pilot test using the Cronbach Alpha test of reliability. The reliability statistics is 0.87 (see the table below), which implies a high level of consistency in the questionnaire in measuring all the variables of the study. Because, Wallen, N. E., (2000) argues if Cronbach's alpha higher than 0.70 indicates internal consistency on the instrument. The following table indicates the test statistic for the Cronbach Alpha test.

\begin{tabular}{|c|c|}
\hline \multicolumn{2}{|c|}{} \\
\hline Cronbach's Alpha & N of Items \\
\hline 0.87 & 40 \\
\hline
\end{tabular}

Source: Survey, 2020

\section{Methods of Data Analysis}

The collected data were first checked for consistency, completeness, missing, and other errors before the entry process. The data coding makes ready the completed and correct questionnaire for analyzing process. A data entry outline was organized, and data was entered into the appropriately designed program for analysis. Therefore, data has been analyzed by descriptive and inferential statistics using Statistical Package for Social Science (SPSS-version 20). Descriptive statistical indexes like percentage, mean and standard deviation are used for analyzing. Similarly, inferential statistics such as correlation and multiple linear regressions were also used to identify the strength of the relationship and the degree of prediction between independent and dependent variables (fiscal decentralization). The mathematical model of multiple regressions below was used to determine the quantitative association between the variables:

$\mathbf{Y}=\mathbf{B}_{0}+\mathbf{B}_{1} \mathbf{x}_{1}+\mathbf{B}_{2} \mathbf{X}_{2}+\mathbf{B}_{3} \mathbf{X}_{3}+\mathbf{B}_{\mathrm{n}} \mathbf{x}_{\mathrm{n}}+\mathbf{E}$

Where $\mathbf{Y}=$ Dependent Variable,

$\mathbf{X}=$ represents the explanatory (Independent) Variable in the estimation model.

$\mathbf{B}_{0}=$ constant

$\mathbf{B}_{\mathbf{n}}=$ Coefficient

$\mathbf{E}=$ represents the error term 


\section{Regression Assumption Tests}

Different assumption tests were considered before applying multiple linear regression models to ensure the appropriate use of data analysis. Those assumption tests include normality, linearity, and multicollinearity tests. Lastly, based on those tests, there was no normality, linearity, and multicollinearity problem to proceed to the multiple linear regressions.

\section{Model Specification}

This study used multiple linear regression models to assess the relationship between the variables in practices of fiscal decentralization at the study area. Thus:

\section{$\mathrm{PFD}=-.161 \mathrm{LF}+0.071 \mathrm{ET}+-.164 \mathrm{Rev}+0.236 \mathrm{Ex}+.525 \mathrm{EE}+0.172 \mathrm{CM}+0.19 \mathrm{FTs}$}

\section{Where,}

* $P F I=$ Dependent Variable

* Variables written in bold are independent variables.

\section{Result and Discussion}

The objective of this research paper is to assess the practice and challenges of fiscal decentralization in the Bedelle Woreda: mainly, by taking five selected basic public sectors of the woreda under study. The data were gathered through questionnaires, key informant interviews, and document analysis. The data collected from the target population was analyzed using SPSS version 20.

The study participants' responses regarding independent and dependent variables and the demographic profile of the respondents are summarized using frequencies and percentages. In addition, multiple regression analysis was used to measure the relationship between of independent variable on the dependent variable.

\section{Legal Frameworks of Fiscal Decentralization in the Study Area}

The Federal Democratic Republic of Ethiopia (1995) laid the foundation for autonomy and introduced decentralized government systems (Mulugeta, 2012). In line with this, by 2002, the 
regional block grant has been introduced so that districts can finance their expenditure needs. Different capacity-building efforts were also made in view of the weak implementation capacities observed in the processes of district decentralization (Worku, 2005; Desalegn, 2015).

The results show that most respondents are not satisfied with the existing legal framework placed to implement fiscal decentralization at the sector level. In light of this, the responses gained from study participants, $33.1 \%$ and $20.7 \%$ of respondents strongly disagree and disagree on the level of satisfaction with the existing legal framework placed to implement fiscal decentralization at sectors level, respectively. This indicates that $53.8 \%$ of respondents are not satisfied with the existing legal frameworks to implement fiscal decentralization at the sectoral level. However, $12.4 \%$ and $24.8 \%$ of the respondents responded strongly agree and agree, respectively. This shows that $37.2 \%$ of the respondents were generally satisfied with the existing legal frameworks to implement fiscal decentralization at the sector level. The rest, $9.1 \%$ of respondents, remained undecided regarding the same issue.

In addition to this, the data collected from key informants through interview revealed that the existing legal frameworks to implement fiscal decentralization in sector level, is not satisfactory, for instance, as rural road sector office response, the rural road construction rate principle is not updated with the current situation of contractors. Because, rate principle is developed since 2006/14, but today, everything is changed more than the folds of the then time. This situation affects the effective implementation of fiscal decentralization in the sector office.

Again, the research conducted by Eyob (2017) confirms that the local government is trying to implement institutional and legal frameworks, which it adopted to establish effective woreda level decentralization; however, there is still lacking a proper implementation of fiscal decentralization.

\section{Revenue Generation and Utilization of Selected Sectors of Bedelle Woreda}

The revenue assignment is an important element of fiscal decentralization. If fiscal decentralization is a reality, sensational governments must control their source of revenue which is the essence of decentralization (Yilmaz 2001; Box and Heredia 2005; Mahat, 2007). In this regard, the result of the questionnaires respondent shows that $17.4 \%$ and $26.4 \%$ of the respondent responded that they strongly disagree and disagree, respectively, with the issue of sector offices internally generate adequate revenue to cover some own expense. This shows that, 


\section{PanAfrican Journal of Governance and Development, Vol. 2, No. 2, August 2021}

in aggregate, $43.8 \%$ of the respondents said there is no adequate revenue internally generated to cover some own expense of the sector office whereas $25.6 \%$ and $17.4 \%$ of respondents strongly agreed and agreed on the same issue, respectively. Aggregately, $43 \%$ of the respondents said that the sectors internally generated adequate revenue to cover some own expense of their sector office while the rest, $13.2 \%$ of respondents, remained undecided regarding the same issue. Generally, the result implies that sector offices have no internally generated revenue to cover some expenses. With this regard, the literature confirms that, in many developing countries, local governments or administrative units possess the legal authority to impose taxes. However, the tax base is so weak and the dependency over the central government subsidies so deep-rooted that no attempt is made to exercise their authority (Smith 2011).

\section{Expenditure Authority and Responsibility of Selected Sectors}

Assigning expenditure responsibilities to local government increases economic efficiency as local governments can provide better services due to proximity and informational advantages (Rodrigues, A., and A. Kroijer, 2009). In this regard, the result shows that $34.7 \%$ and $27.3 \%$ of the respondents responded that they strongly agree and agree with the sector's issue of autonomy in decision-making on expenditure assignment. The sum of both, $62 \%$ of the respondents said the sector has autonomy in decision-making on expenditure assignment. Whereas $24 \%$ and $10.7 \%$ of respondents responded strongly disagree and disagree, respectively. Moreover, the remaining $3.3 \%$ of respondents were undecided on the same issue. This implies that the sectors have autonomy in decision-making on expenditure assignment.

In contrast, literature on this issue indicates that the assignment of expenditure responsibilities and decision-making power to lower levels of government is one of the basic arguments in the theory of fiscal decentralization that improves the local government capacity to efficiently identify and address the needs of their citizens (Demelash, 2011). Hence, the researchers concluded that what is observed in the study area is not in line with existing fiscal decentralization literature. The woreda government needs to means appropriate frameworks to make decisions on spending revenue, as they are at the forefront of responding to the demands and preferences of the local people.

\section{Expenditure and Revenue trends in the Selected Public Sectors of Bedelle Woreda}

The arguments and principles of fiscal decentralization require the sectors to generate their

revenue and exercise adequate expenditure responsibilities (Minhaj A and Dabela B, 2018). In 
this argument, this study attempted to assess the share, revenue, and dependence average of five consecutive fiscal years Bedelle woreda selected public sectors under study.

\begin{tabular}{|l|l|l|l|}
\hline Name of Sectors & $\begin{array}{l}\text { Average of sectors } \\
\text { share from woreda } \\
\text { budget in \% }\end{array}$ & $\begin{array}{l}\text { Average of internal } \\
\text { revenue raised by } \\
\text { sector in \% }\end{array}$ & $\begin{array}{l}\text { Average of dependence } \\
\text { on grant in \% }\end{array}$ \\
\hline Education & 34.86 & 0.63 & 99.37 \\
\hline Agriculture & 19.72 & 0.866 & 99.13 \\
\hline Health & 11.20 & 0 & 100 \\
\hline Road & 5.35 & 4.95 & 95.05 \\
\hline Water & 2.39 & 5.28 & 94.72 \\
\hline
\end{tabular}

Source: Survey 2020

\section{Note}

$\checkmark 73.52 \%$ of the five-year budget was allocated for these sectors in five consecutive years.

$\checkmark \quad 97.65 \%$ sectors were depended on grant

$\checkmark 2.35 \%$ of the sectors raised internal revenue

The woreda understudy, in consecutive five years:

$\checkmark \mathbf{8 4 . 5 4 \%}$ depend on grant

$\checkmark \mathbf{1 5 . 4 6 \%}$ internally raised revenue.

\section{The Factors Affect Effective Revenue Generation and Expenditure Decision in Study Area}

\section{The Employee's Experience on Program}

Local governments lack the capacity and experience to attract and retain the right talent of staff to articulate plans and execute programs and projects in order to transform the lives of the grassroots people (Fosu, 2012). In this regard, the study results show that $16.5 \%$ and $30.6 \%$ of the respondent responded that they strongly disagree and disagree, respectively, with the issue of the sector employee's experience concerning revenue autonomy of the sectors is satisfactory. This indicates that, in aggregate, $47.1 \%$ of the respondents believed that the sector's employee's experience on the program is not satisfactory whereas $24.8 \%$ and $8.3 \%$ of respondents strongly agreed and agreed on the same issue, respectively. Rest $19.8 \%$ of respondents remained undecided regarding the same issue. The variable realized a mean of 2.94 and a standard deviation of 1.434, implying that the sector's employee's experience on the program is not satisfactory. 


\section{PanAfrican Journal of Governance and Development, Vol. 2, No. 2, August 2021}

\section{The Woreda Top Management Commitment on Program}

Shah (2013) adds that local revenue mobilization has the potential to foster political and administrative accountability by empowering communities. However, prescriptions deriving from the theory and good international practice impose huge factors on local governments' choice of revenue instruments. Olowu (2003) reveals that the reason for poor local authorities' revenue mobilization includes weak administration, which, combined with a lack of commitment of managers for enforcement, generates a low level of local revenue mobilization performance. In this regard, the result shows that $29.8 \%$ and $25.6 \%$ of the respondents responded that they strongly agree and agree with the top management issue effectively discharge their responsibility and inadequacy on the budget transfer from the top. This shows that $55.4 \%$ of the respondents believed that the top management effectively discharged their responsibility inadequacy on the budget transfer from the top whereas $21.5 .5 \%$ and $16 \%$ of respondents strongly disagreed and disagreed, respectively, on the same. The rest, $6.6 \%$, were remaining undecided on the same issue. The result implies that the top managers effectively discharge their responsibility inadequacy on the budget transfer from the top.

Similarly, the review literature also confirms that successful pro-poor decentralization is associated with governing parties that are politically committed to the democratic empowerment of local governments. Decentralization cannot occur until the highest political authority supports it.

\section{The Employee's Training on Program}

Shortage of well-trained and qualified personnel that are supposed to serve as a tool for collecting taxes and rates at the local level, even the few available are not adequately trained in efficient budgetary and financial management systems (Armstrong, 2009). In this regard, the result shows that $33.9 \%$ and $17.4 \%$ of the respondents responded that they strongly disagree and disagree, respectively, with the issue that training is given for concerned employees concerning the internal revenue-raising of sector office is effectively practiced. This shows that, in aggregate, $51.3 \%$ of the respondents believed that no training is given for concerned employees concerning internal revenue rising in the sectors whereas $28.1 \%$ and $8.3 \%$ of respondents strongly agreed and agreed on the same issue. Then, the rest, $12.4 \%$, remained undecided on the same issue. This shows that training is not given for concerned employees concerning the rising internal revenue of the sector office, so it is not effectively practiced. 
As the response of key informants of the study, the sectors have not been capacitated to generate sufficient internal revenue to cover some part of their expenses because of lack of training and workshop to concerning bodies like; local communities and the sector's employees about internal revenue mobilization and its benefits for local communities. This leads the sectors to depend on the regional grant highly. Similarly, the study conducted by Ali (2018) confirms that the local government lacks a budget allocated to staff training. This could be attributed to a lack of adequate funding for public services and fiscal autonomy at the local level.

\section{Inter-Governmental Fiscal Transfer (GIFT)}

To fill the fiscal gap, governments typically seek to provide a range of predictable and transparent sub-national transfers (for example, block, equalization, and conditional grants) that enable local authorities to meet their recurrent and investment needs (International Development Agency, 2005). Results revealed that $29.8 \%$ and $28.9 \%$ of the respondents strongly disagree and disagree, respectively, for the satisfaction to the extent of fiscal transfers. This indicates that, in aggregate, $59.6 \%$ of the respondents believed that they are not satisfied with the extent of fiscal transfers from the top tier of the government to the sector/woreda whereas $12.4 \%$ and $19 \%$ of respondents strongly agreed and agreed on the same issue, respectively. The rest, 9.9\% of respondents, remained undecided regarding the same issue. The results show that most respondents are not satisfied with the extent of fiscal transfer from the top tier of the government to the sector/woreda. However, literature on this issue revealed that intergovernmental fiscal relations must be thought of as a fiscal system, and all the pieces of that system must fit together (Bird, 2003).

\section{The Challenges and Constraints to Practice Fiscal Decentralization in the Study Area}

On the program of Woreda-level fiscal decentralization in Ethiopia, there are various institutional, administrative, and political challenges, International Development Agency (2004). However, the Ethiopian government has introduced constitutional, administrative, and institutional reforms to deepen and broaden the decentralization process to Woreda through Woreda/ District/ Level Decentralization Program (DLDP) in 2001. However, the woreda under discussion faces some institutional and legal framework problems to implement fiscal decentralization at the local level. In this regard, the study indicates that $25.6 \%$ and $24.8 \%$ of the respondents strongly disagree and disagree, respectively, or in aggregate, $50.4 \%$ of the 


\section{PanAfrican Journal of Governance and Development, Vol. 2, No. 2, August 2021}

respondents generally agreed that the main challenges of fiscal decentralization application in woreda is the legal framework. However, $20.7 \%$ and $26.4 \%$ of the respondents strongly agree and agree, respectively, that the major challenges of fiscal decentralization in the study area are legal frameworks. This implies that out of the total respondents, $41.7 \%$ of respondents disagree and strongly disagree that the main challenges of fiscal decentralization are the legal framework. Besides, $2.5 \%$ percent of respondents responded as undecided about the issue.

The study further revealed that the other bottlenecks of fiscal decentralization lack logistics and supply at the local level, including the study area. In this regard, the result shows from table 28 the $57 \%$ and $26.4 \%$ of the respondent responded that they strongly agree and agree, respectively, with the main constraint of fiscal decentralization application of the woreda is a lack of logistics and supply. This shows that, in aggregate, $83.4 \%$ of the respondents agreed that the main constraint of fiscal decentralization application of the woreda is a lack of logistics and supply, whereas $6.6 \%$ and $9.9 \%$ of respondents strongly disagreed and disagree respectively on the same. Moreover, the information from key informants of the study revealed that logistics in the sector is a severe problem. The operational cost allocated to the sector for maintenance, oil gas of car, motor bicycle, and other logistics facilities is very low from woreda. Even, there is almost no transportation facility to follow up and supervise the activities going on in the kebeles of the woreda under concerned sectors. For instance, the water sector has only one motor bicycle to follow up and supervise the 41 kebeles of the woreda. Among kebeles, some are found $42 \mathrm{~km}$ from the center of woreda.

Furthermore, lack of logistics supply in the health sector is a severe problem in the sector office. To address services and make continuous supervision, there is a lack of adequate transportation, like the car, motor bicycle, fuel, lack of money for maintenance, etc. The researchers also observed the broken car, which is the possession of the sector, but it is not maintained due to lack of budget.

The devolution of power to districts is one of the major challenges in its implementation has been the problem related to the availability and the quality and quantity of manpower. In this regard, the study shows that $46.3 \%$ and $19.8 \%$ of the respondents responded that they strongly agree and agree that the main problem related to the practical implementations of fiscal decentralization in the sector is manpower. Aggregately, 66.1\% agreed on manpower problems in the sectors under study, whereas the $11.6 \%$ and $9.9 \%$ of respondents, a sum of $21.5 \%$, strongly 
disagreed and disagreed on the same issue. In contrast, the rest, $12.4 \%$ of respondents, remained undecided regarding the same issue.

The key informants' data indicates that the sector's lack of sufficient human resources is the main problem of implementing fiscal decentralization. It indicates that the lack of manpower is a severe problem in the Bedelle woreda health office. For instance, the needed human power in the water sector is 38 , but the actual human resource is 12 . Moreover, the sector has only one maintenance expertise for 41 kebeles of the woreda. In the health sector, the needed manpower is 53 , but the actual expertise is 13 on average. Whereas in the agriculture sector, the needed manpower for all kebele is 123 expertise, which means one kebele three expertise, (1:3) but actual expertise is $96,(1: 2)$. Furthermore, the woreda needs eight crop production expertise, but the actual crop production expertise is only 3 for all 41 kebeles.

The other severe challenge of the practice of fiscal decentralization is a significant mismatch between its expenditure obligation and the financial resources it receives in the form of the block grant and use of its own revenue. In this regard, the result of the study indicates that $48.8 \%$ and $23.1 \%$ of the respondents strongly agree and agree, respectively, or in aggregate, $71.9 \%$ of the respondents generally agreed that the main constraints related to the practical implementations of fiscal decentralization in sectors are financial resources. However, 5\% and $13.2 \%$ of the respondents strongly disagree and disagree, respectively, that the major challenges of fiscal decentralization in the study area are financial resources. While the rest, $9.9 \%$ of respondents, responded that they were undecided about the issue.

Last but not least, the challenge of implementing fiscal decentralization at the districts level is a lack of autonomy. Districts could not exercise sufficient local autonomy, and the performance of the districts as effective units of government has been constrained by a number of inter-related factors (Meheret, 2007). In this regard, the result of the study shows that $69.4 \%$ of the respondent responded that the main source of sector revenue in the budget from the top government, while $20.7 \%$ of the respondent responded that the main source of sector revenue is from different NGOs, whereas $5.8 \%$ and $4.5 \%$ is from school grant and other sources respectively. It proves that $95.9 \%$ in aggregate, the sector depends on the top government and NGOs, while $4.1 \%$ of the sector budget is internally mobilized. 


\section{PanAfrican Journal of Governance and Development, Vol. 2, No. 2, August 2021}

The secondary data refers, i.e., document from the woreda office of finance and economic development and the woreda revenue authority confirms the high dependence of the woreda budget on regional government. The woreda revenue authority raised revenue maximum of 16 million in the five consecutive fiscal years, specifically in 2011/19. It proves the high dependency of Bedelle woreda on the grant budget from the Regional government average of $\mathbf{8 4 . 5 4 \%}$ in the consecutive fiscal year under study. In the five consecutive fiscal, years the Bedelle woreda raised and collected the maximum of 16 million Ethiopian Birr (ETB) during the fiscal year of 2011/19, and the cumulative average of collected revenue during consecutive fiscal year understudy was $\mathbf{1 5 . 4 6 \%}$ only.

Similar to these findings, Eyob A (2017) found insufficient administration and institutional capacity, top-down decision and authority structures afflicting the state system, and the absence of transparency and accountability at the local level. Again, Girma, D (2018), in Ethiopia, the practices of fiscal decentralization show that there is high vertical fiscal imbalance and regional disparities, the problem of effectiveness and efficiency in resource utilization, problems of administrative malpractice, and tight political influence mainly at local levels. In conclusion, the researchers believe that the woreda government should alleviate the challenges and implement fiscal decentralization effectively.

\section{Regression Assumption Test}

Before applying the multiple linear regression analysis to test the influence of independent variables on fiscal autonomy, some tests were conducted in order to ensure the appropriateness of data analysis as follows:

\section{Normality Test}

The main assumption in normality is that the data distribution in each item and all linear combinations of items is normally distributed (Tabachnick and Fidell, 2007; Hair et al., 2010). The researcher used the histogram method of testing the normality of the data. The histogram is bell-shaped, which implies that the residuals (disturbance or errors) are normally distributed. The residuals should be normally distributed about the predicted dependent variable score. As shown in the figure below, the dependent variable is normally distributed for each value of the independent variables. 


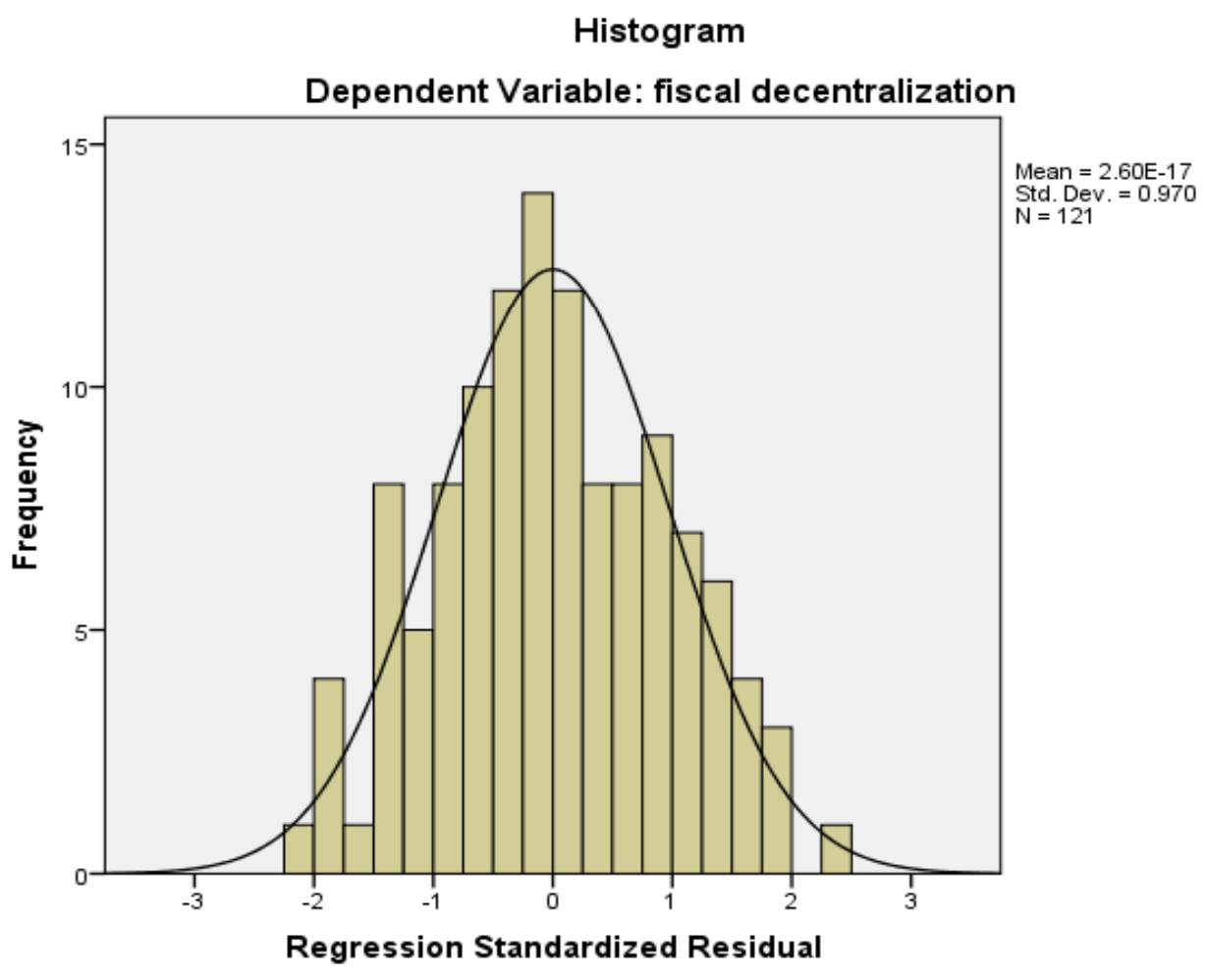

\section{Linearity Test}

Linearity means the correlation between variables, which is represented by a straight line. Knowing the level of the relationship among variables is considered an important element in data analysis. It is crucial to test the relationship of the variables to identify any departure that may impact the correlation (Tabachnick and Fidell, 2007). Linearity refers to the degree to which the change in the dependent variable is related to the change in the independent variables. To determine the relationship between the independent variables such as legal framework, employee training, revenue-raising, expenditure responsibility, employee experience, management commitment, fiscal transfers, and dependent variable fiscal decentralization is linear, plots of the regression residuals through SPSS software had been used. In linearity, the residuals should have a straight line relationship with predicted dependent variable scores.

As shown in the figure below, the change in the dependent variable is more related to the independent variables' change. Therefore, there is no linearity problem on the data for this study, and residual follow at a straight line. 
PanAfrican Journal of Governance and Development, Vol. 2, No. 2, August 2021

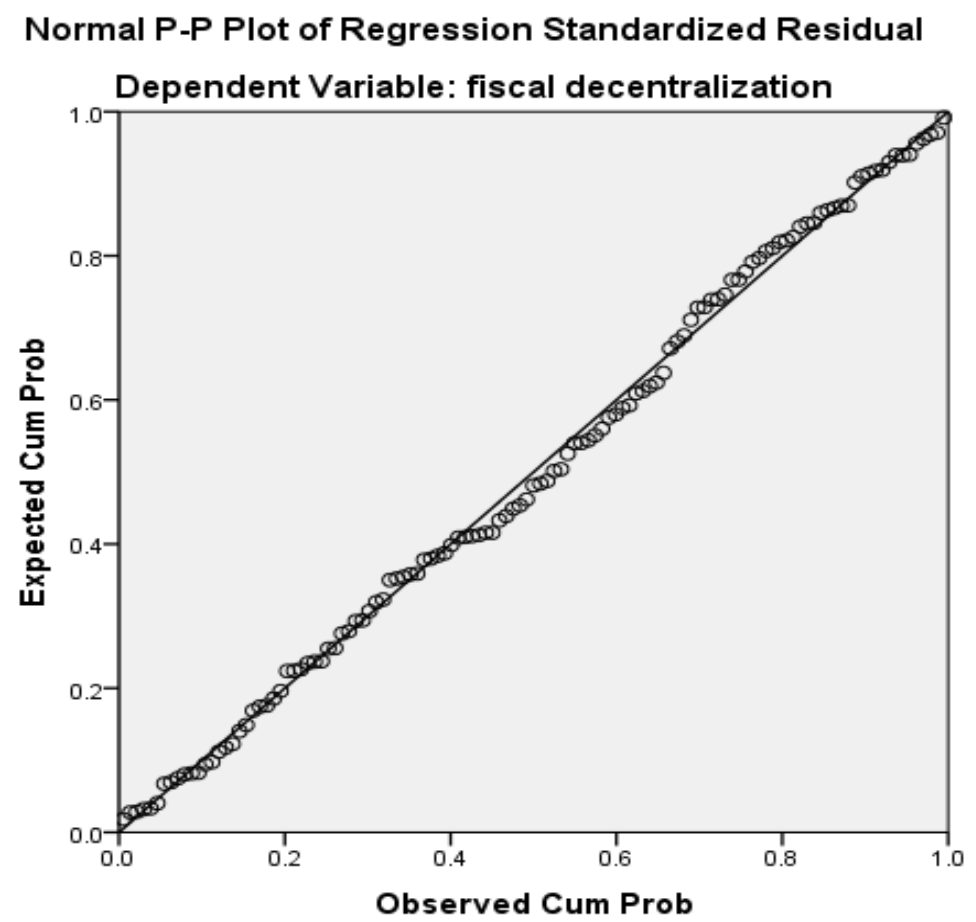

The regression model assumption of linearity in the study

Source: Survey, 2020

\section{Multicollinearity Test}

Multicollinearity means that two or more of the independent variables are highly correlated, and this situation can have damaging effects on the results of multiple regressions (Hair et al., 2010). The Variance Inflation Factors (VIF) of the linear regression indicate the degree that the variances in the regression estimates are increased due to multicollinearity. Therefore, the Collinearity statistics show that the Variance Inflation Factors (VIFs) ranged from 1.021 to 1.130 , and tolerance values ranged from 0.885 to 0.979 , as described below.

\begin{tabular}{lll}
\hline Model & \multicolumn{2}{l}{ Collinearity Statistics } \\
\cline { 2 - 3 } & Tolerance & VIF \\
\hline (Constant) & .939 & 1.064 \\
Legal framework & .885 & 1.130
\end{tabular}



Decentralization...

\begin{tabular}{lcc} 
Revenue raising & .956 & 1.046 \\
Expenditure responsibility & .907 & 1.103 \\
Employee Experience & .942 & 1.061 \\
Commitment of management & .908 & 1.101 \\
Fiscal transfer & .979 & 1.021 \\
\hline a. $\quad$ Dependent Variable: Fiscal decentralization & \\
b. Independent Variables: Legal framework, Employee Training, Revenue raising, Expenditure responsibility, \\
\multicolumn{2}{l}{ Employee Experience, Commitment of management, and Fiscal transfer. }
\end{tabular}

Source: Survey, 2020

Field (2005) stated that the Variance Inflation Factors (VIF) of the linear regression indicated the degree that the variances in the regression estimates are increased due to multicollinearity and VIF values higher than 10 , which shows us there is a multicollinearity problem. As Pallant (2007) stated, tolerance is a statistical tool that indicates the variability of the specified independent variable from other independent variables in the model. It has no multicollinearity problem if the tolerance is more significant than 0.10 values. Tolerance and VIF results suggest that multicollinearity is not suspected amongst the independent variables because the values of Variance Inflation Factors (VIF) are below 0.10 while the tolerance values are above 0.10 .

\section{Multiple Linear Regression Analysis}

Hair. et al. (2007), multiple regression analysis is a form of general linear modeling and is an appropriate statistical technique when examining the relationship between a single dependent variable and several independent variables (predictors).

The table below shows, the R-value obtained by regression is .669 , and the $\mathrm{R}$ square value is, which means that all independent variables have explained $44.8 \%$ variations in fiscal decentralization, and $55.2 \%$ was due to other factors.

The R-value obtained by regression is .669, and the $\boldsymbol{R}$ square value is . 448 , which means that the all-independent variables have explained $44.8 \%$ variation in fiscal decentralization and $55.2 \%$ was due to other factors. It is explained in the following model summary table.

\begin{tabular}{lllll}
\hline Model & R & R Square & Adjusted R Square & Std. Error of the Estimate \\
\hline
\end{tabular}


PanAfrican Journal of Governance and Development, Vol. 2, No. 2, August 2021

\begin{tabular}{lllll}
\hline 1 & $.669^{\mathrm{a}}$ & .448 & .414 & .342
\end{tabular}

Source: Survey, 2020

a. Predictors: (Constant) Legal framework, Employee Training, Revenue raising, Expenditure responsibility, Employee Experience, Commitment of management, and Fiscal transfer

b. Dependent Variable: Fiscal decentralization

The Analysis of Variance (ANOVA) results of the regression between predictor variables and fiscal decentralization shows that the probability value of $0.000(\mathbf{p}<0.05)$ indicates the relationship was highly significant in predicting how dependent explain fiscal decentralization. It is explained in the following Regression ANOVA Results table.

\begin{tabular}{llccll}
\hline \multicolumn{1}{c}{ Model } & Sum of Squares & df & Mean Square & F & Sig. \\
\hline Regression & 10.522 & 7 & 1.503 & 12.603 & $\mathbf{. 0 0 0}^{\mathbf{b}}$ \\
Residual & 13.478 & 113 & .119 & & \\
Total & 24.000 & 120 & & & \\
\hline
\end{tabular}

Source: Survey, 2020

\section{Results of Multiple Linear Regression Model for Independent Variables}

On the other hand, the P-value can explain the variation in the dependent variable. When the Pvalue is less than 0.05 , the independent variables explain the variation in the dependent variable. Whereas, when the P-value is greater than 0.05 , the independent variables do not explain the variation in the dependent variable. To this effect, since $P$-value is $0.000(p<0.05)$, all independent variables explaining the variation in the dependent variable (fiscal decentralization). It is explained in the following multiple regression coefficients result table.

\begin{tabular}{|l|c|c|}
\hline \multicolumn{1}{|c|}{ Independent variables } & Coefficients (B) & P-Values \\
\hline Legal framework & -.161 & .059 \\
\hline Employee's Training & .071 & .404 \\
\hline
\end{tabular}




\begin{tabular}{|l|c|c|}
\hline Revenue raising & -.164 & .025 \\
\hline Expenditure Decision & .236 & .002 \\
\hline Employee Experience & .525 & .000 \\
\hline Commitment of Management & .172 & .020 \\
\hline Fiscal transfer & .019 & .791 \\
\hline
\end{tabular}

Source: Survey 2020

The Beta Coefficient (B) result shows the strength of the effect of each independent variable to the dependent variable (fiscal decentralization), as shown in the above table. The Mathematical Model of multiple regressions below can be used to determine the quantitative association between the variables:

$$
\mathbf{Y}=\mathbf{B}_{0}+\mathbf{B}_{1} \mathbf{X}_{1}+\mathbf{B}_{2} \mathbf{X}_{2}+\mathbf{B}_{3} \mathbf{X}_{3}+\ldots \mathbf{B}_{\mathbf{n}} \mathbf{X}_{\mathbf{n}}
$$

Where

$\mathbf{Y}=$ dependent Variable,

$\mathbf{B}_{0}=$ constant

$\mathbf{B}_{\mathbf{n}}=$ Coefficient

$\mathbf{x}_{\mathbf{n}}=$ represents the Independent Variables in the estimation model.

\section{Interpretation of Multiple Linear Regression Model Result}

The internal revenue-raising negatively influences the dependent variable and is significant at a $5 \%$ probability level in the study area. Therefore, when internal revenue rising decreased by 1 percent, the fiscal decentralization will decrease by $16.4 \%$, keeping the other factors constant. Employee Experience has a positive influence on fiscal decentralization; When Employee Experience increases by 1 percent, the fiscal decentralization will increase by $52.5 \%$, keeping the other factors constant.

Similarly, management's commitment has a positive influence on the dependent variable and is significant at a $5 \%$ probability level. As the commitment of management increase by 1 percent, the fiscal decentralization will increase by $17.2 \%$, assuming the other variable is held constant. 


\section{PanAfrican Journal of Governance and Development, Vol. 2, No. 2, August 2021}

Expenditure decision positively influences the dependent variable and is significant at a $5 \%$ probability level. As expenditure decisions increase by 1 percent, the fiscal decentralization will increase by $23.6 \%$, assuming the other variable is constant.

\section{The Major Findings of the Study}

$>$ The study revealed the problem of autonomy to plan the budget in line with the sector demand and conduct their own activities in line with the needs and interests of their jurisdiction. Regarding legal framework, the response of key informants of the concerned sectors is dissatisfied with the existing legal framework to implement effective fiscal decentralization.

$>$ The study found that the woreda's internal revenue generation and utilization are very low and the revenue utilization of the sectors under discussion. There is a high dependence of woreda on regional government, accounting for more than $\mathbf{8 4 . 6 \%} \%$ and $\mathbf{9 7 . 6 \%}$ for sectors. It implies there is no fiscal autonomy in the woreda.

$>$ The study found that there was no sufficient training and capacity building given to the employee in mobilizing revenue at the sector level and lack of employee training affects revenue raising and fiscal autonomy of the woreda.

> Concerning the sector's autonomy in expenditure assignment, the study found that sectors sector has autonomy in decision-making on expenditure assignment.

$>$ The employee experience on the program of fiscal decentralization affects the sector's fiscal decentralization practice, like a low level of internal revenue generation of their own expense. The lack of commitment of managers of the concerned offices of woreda affects the effective practice of fiscal decentralization in the study area.

$>$ The study revealed that the fiscal transfer to filling fiscal imbalance among sectors of the study area is weak, and also, the extent of fiscal transfer for the concerning sector was unsatisfactory.

$>$ The study found that the practice of fiscal decentralization in the woreda sectors is facing challenges. These include:

$\checkmark$ Inadequate institutional and administration frameworks,

$\checkmark$ lack of well-trained local government personnel,

$\checkmark$ Lack of commitment,

$\checkmark$ Lack of manpower, 
$\checkmark$ Financial problem and limited autonomy,

$\checkmark$ The absence of transparency and accountability at the local level were major challenges.

\section{Conclusion and Recommendations}

\section{Conclusion}

$>$ Based on the study's summary, the existing legal framework to implement fiscal decentralization at the sector level is unsatisfactory.

$>$ Revenue generation and utilization of the woreda and selected sectors is very low. Because of insufficient training and capacity building given to the employee in mobilizing revenue rising at the sector level, it leads to a high fiscal imbalance in the program.

$>$ Employee experience and management commitment to the fiscal decentralization program affect the effective practice of fiscal decentralization in the study area.

$>$ The fiscal transfer to filling fiscal imbalance among sectors is weak, and the extent of fiscal transfer for the concerning sector is unsatisfactory.

$>$ Based on the coefficient of Beta value (B), the revenue-raising is negatively predicting fiscal decentralization while employee experience is more positively predicting fiscal decentralization than the other variables in the study area.

$>$ Generally, the practice of fiscal decentralization in the woreda sectors faces a number of challenges like; inadequate institutional and capacity shortages, lack of well-trained local government employees, and budget insufficiency were the main challenges of fiscal decentralization.

\section{Recommendations}

Based on the study findings, the following major recommendations are forwarded:

$>$ Government should develop relevant legal and institutional frameworks for woreda and sectors to make sufficient decision-making power, serve as autonomous units, and manage the service provisions in their areas to maximize the benefits of local residents.

$>$ Woreda government should provide capacity building to the employee through shortand long-term training and workshop for the sector staff and concerned body to smoothly implement fiscal decentralization at the local level. 


\section{PanAfrican Journal of Governance and Development, Vol. 2, No. 2, August 2021}

> The Woreda government has the authority to generate and utilize revenue from its sources, which is recognized by law; therefore, the woreda should ultimately use power to raise revenue through a revenue mobilization program to reduce budget dependence syndrome.

$>$ The Woreda top management should follow up the expenditure decision of the sectors and encourage internal revenue generation of sectors in order to promote local fiscal autonomy.

$>$ The Woreda government should provide motivational incentives for responsible employees and preparing revenue mobilization programs in different sectors and

$>$ The top government should consider the extent of fiscal imbalance at the local level and transfer the necessary budget to fill the gap.

$>$ To make an effective fiscal decentralization program, the researchers suggest reducing the challenges listed in the study.

\section{Reference}

Aberra, T. (2015). The extent and impacts of decentralization reforms in Ethiopia. Theses \& Dissertations, Boston University.

Abraham, G. (2011). Assessment on the Implementation of Woreda Decentralization in Gambella Regional State. Addis Ababa, Ethiopia.

Abu, G. (2005). Fiscal Federalism and Its Discontents: Theory and Policy. 3rd EAFEARO/CADPR-WMU International Symposium on Ethiopian Development Studies, Addis Ababa, Ethiopia.

Alam, M. \& Girma Ch. (2017). Challenges and Opportunities of Fiscal Decentralization in Sidama Zone. Indian Journal of Politics 51(3\&4).

Ali, A. A. (2018). Factors affecting Decentralization of Public Sector Services on Local Governance of Puntland: Case of Garowe District. Kenya: Jomo Kenyatta University of Agriculture and Technology.

Azfar, O., et al. (2005). Decentralization, Governance and Public Services: The Impact of Institutional Arrangements. IRIS Center, University of Maryland, College Park.

Bird, Richard M. (2008). Asymmetric Fiscal Decentralization: Glue or Solvent? Georgia State University, United States of America.: International Studies Program, Andrew Young School of Policy Studies, Working Paper 03-09.

Boschmann, N. (2009). Fiscal Decentralization and Options for Donor HarmonizationDevelopment Partners Working Group on Local Governance and Decentralization. Berlin, Germany.

Deribe, A. (2015). Fiscal Decentralization in Ethiopia: Achievements and Challenges. Ethiopian Civil Service University: Public Policy and Administration Research,

Eyob, A. ( 2017 ). Appraisal of Woreda-Level Fiscal Decentralization in Addis Ababa City Government. 
FDRE. (1995, December 08). Federal Democratic Republic Constitution of Ethiopia. Addis Ababa.

Litvack, J. J. (2005). Rethinking Decentralization in Developing Countries. Washington, DC: The World Bank.

Mbedzi and Gondo. (2010). Fiscal Management in Dangila Municipality, Ethiopia. Washington, DC.

Minhaj A and Dabela B. (2018). Assessment of Fiscal Decentralization in Ethiopia; The Case Study of Sibu Sire Woreda, East Wollega Zone, Oromia Regional State;. Jurnal Studi Pemerintahan 10 (2). DOI: https://doi.org/10.18196/jgp.102101.

Neven, I. (2002). Background paper on decentralization. National Forest Programs in the European Context, Contribution to Cost-Action E19, Institute Alterra. Wageningen, the Netherland: Green World Research.

Oates, W. (1972). Fiscal Federalism. New York.

Smith, H. J. (2012). Fiscal Decentralization and Development: and Analysis of City Governments in Argentina and Mexico, 1980-2010.University Graduate School. Florida International University.

Smoke, Paul. (2009). Fiscal Decentralization in East and Southern Africa: A Selective Review of Experience and Thoughts on Moving Forward. Conference on Fiscal Decentralization.

WorldBank. (2001). Ethiopia Woreda Study. (In Three Volumes) Volume I: Main Phase, Country Office in Ethiopia.

WorldBank. (2010). Ethiopia Public Finance Review. Retrieved from Retrieved from http://documents.worldbank.org/curated/en/530241468255278847/Ethiopia-Publicfinance-review-2010

Zemenu, Y. (2016). Sub-national Fiscal Autonomy in a Developmental State: The Case of Ethiopia. Dire Dawa, Ethiopia.: Haramaya University. 